\title{
Clinical classification of orthostatic hypotensions
}

\author{
William P. Cheshire Jr. ${ }^{1}$
}

Received: 7 March 2017/ Accepted: 8 March 2017/Published online: 27 March 2017

(C) Springer-Verlag Berlin Heidelberg 2017

Measurement of blood pressure (BP) while standing is a frequently overlooked, yet critically important, physical finding in patients with symptoms associated with the upright posture and an essential part of the clinical autonomic evaluation. When and how much of a BP drop should be considered abnormal have been the subjects of ongoing debate, so varied are the physiologic disorders and clinical presentations associated with postural hypotension causing symptomatic hypoperfusion of the retina and brain. The American Autonomic Society's 2011 consensus statement defines orthostatic hypotension $(\mathrm{OH})$ broadly as a sustained reduction of systolic BP of at least $20 \mathrm{mmHg}$ or diastolic BP of at least $20 \mathrm{mmHg}$ within $3 \mathrm{~min}$ of standing or head-up tilt [3].

In this issue, Fedorowski and colleagues investigated orthostatic BP on a tilt table in 1520 patients who were undergoing evaluation for syncope or orthostatic intolerance. They found that systolic BP changes alone were sufficient to identify the $12.2 \%$ of patients who met the consensus diagnostic criteria for $\mathrm{OH}$. Of the 186 patients with $\mathrm{OH}, 176(94.5 \%)$ met the systolic criterion and 102 $(54.8 \%)$ met the diastolic criterion. As only ten (5.4\%) solely met the diastolic criterion, they concluded that, when diagnosing $\mathrm{OH}$ in patients with syncope or orthostatic intolerance, measuring diastolic BP may be unnecessary [1]. Their findings ring true for the selected population they studied, as symptoms of cerebral ischemia correlate most closely with the rate and magnitude of the systolic BP drop. Furthermore, changes in systolic pressure are larger and

William P. Cheshire Jr.

cheshire@mayo.edu

1 Department of Neurology, Mayo Clinic, Jacksonville, FL, USA more easily measured, whereas the Korotkoff sounds demarcating diastolic pressure are softer and can be prone to measurement error.

The meaning of "orthostatic hypotension" as a discrete diagnostic entity also remains soft, as patients with postural $\mathrm{BP}$ changes are diverse in their clinical presentations, and a given BP change that causes symptoms in one patient might not be significant for another. A robust clinical definition draws a valid line between health and disease and balances the need for diagnostic sensitivity with that for specificity. In this respect the diagnostic approach taken by Fedorowski and colleagues may be potentially misleading, as the terminology of $\mathrm{OH}$ in this context appears to conflate orthostatic intolerance with the more common usage of $\mathrm{OH}$ as an indication of noradrenergic failure. Whereas they share a drop in BP, these are disparate entities physiologically, and findings from one group may not be generalizable to the other.

Whether a patient has $\mathrm{OH}$ is an initial clinical determination. The clinician must then assess the magnitude, timing, consistency, and pathophysiology of BP changes to judge whether the $\mathrm{OH}$ is clinically relevant. Diastolic pressure changes, although not always determinative, should not be overlooked, as they may be pertinent in some patients with a mean arterial pressure nadir below the threshold for cerebral perfusion, which corresponds to a mean brachial BP of 60-70 $\mathrm{mmHg}$. Diastolic hypotension, it should be noted, also confers an increased risk for myocardial infarction [2].

If $\mathrm{OH}$ is to remain useful as a concept to describe pathological drops in BP that correlate with postural symptoms, then its variations should be carefully distinguished from one another [3, 7]. Representative hemodynamic profiles of these distinct entities are shown in Fig. 1. 
iOH

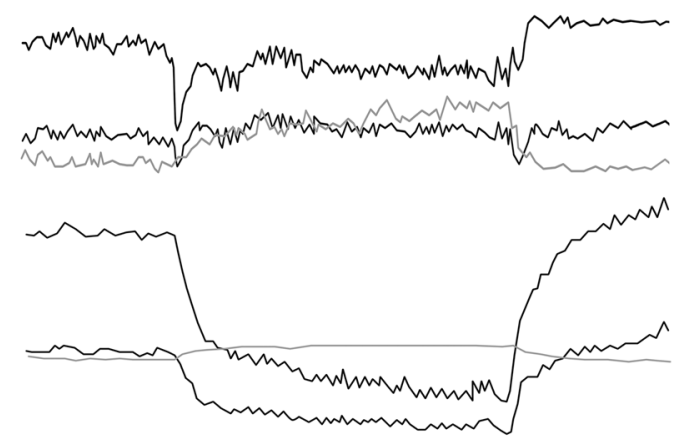

$\mathrm{dOH}$

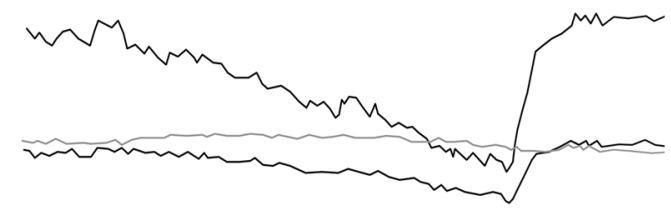

vOH
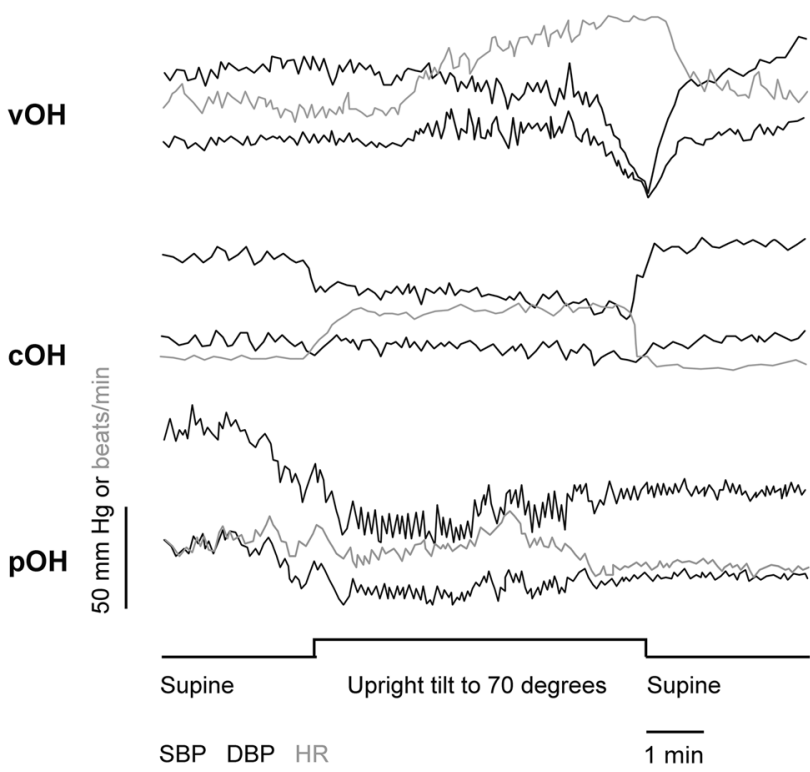

Fig. 1 Beat-to-beat systolic and diastolic blood pressure (SBP and DBP in $\mathrm{mmHg}$, black lines) and heart rate (HR in beats/min, gray lines) responses to upright tilt in representative examples of the various categories of orthostatic hypotension $(\mathrm{OH})$ : initial $\mathrm{OH}(\mathrm{iOH})$, neurogenic $\mathrm{OH}(\mathrm{nOH})$, delayed $\mathrm{OH}(\mathrm{dOH})$, neurally mediated syncope or vasovagal $\mathrm{OH}(\mathrm{vOH})$, cardiovascular $\mathrm{OH}(\mathrm{cOH})$, and pseudo $\mathrm{OH}(\mathrm{pOH})$. The categories may be distinguished by their temporal profiles

Initial orthostatic hypotension (iOH) is defined as a transient BP decrease of $>40 \mathrm{mmHg}$ systolic or $>20 \mathrm{mmHg}$ diastolic with symptoms of cerebral hypoperfusion within $5-15 \mathrm{~s}$ after standing, usually resolving by $20 \mathrm{~s}[5,6]$. This phenomenon, which is common in healthy adolescents and may represent an underrecognized cause of orthostatic syncope in the elderly, is more pronounced during active standing than passive tilting [3]. Symptoms correlate more closely with systolic than diastolic BP changes.

Neurogenic orthostatic hypotension $(\mathrm{nOH})$ is defined as a sustained BP decrease of $>20 \mathrm{mmHg}$ systolic or
$>10 \mathrm{mmHg}$ diastolic, with or without symptoms, within 3 min of standing or head-up tilt [3]. In nOH sympathetic noradrenergic nerves consistently fail to mediate the reflexive cardiovascular responses necessary to maintain $\mathrm{BP}$ in response to orthostatic stress. Sympathetic noradrenergic failure can occur peripherally at sympathetic ganglia or at postganglionic sympathetic neurons innervating vascular adrenoceptors, or centrally in brain or spinal cord pathways that regulate sympathetic outflow. The differential diagnosis includes the $\alpha$-synucleinopathies: multiple system atrophy, pure autonomic failure, and Parkinson disease; dopamine $\beta$-hydroxylase deficiency; autoimmune autonomic ganglionopathy; and autonomic neuropathies, especially those caused by amyloidosis and diabetes. These patients also have impaired noradrenergic responses to the Valsalva maneuver.

Delayed orthostatic hypotension $(\mathrm{dOH})$ is defined as a fall in $\mathrm{BP}$ that fulfills the criteria for $\mathrm{nOH}$ but occurs after $3 \mathrm{~min}$. This may indicate an early or milder form of noradrenergic failure or a contribution from such factors as antihypertensive medications, venous pooling, transcapillary filtration of fluid, or impaired neurohumoral responses [4].

Neurally mediated syncope ( $\mathrm{vOH})$, also known as vasovagal or vasodepressor syncope, consists of a complex set of phenomena that include paroxysmal withdrawal of sympathetic vasopressor tone, often during prolonged standing, in patients who otherwise have a normally functioning autonomic nervous system. Following an interval of normal BP in the upright posture, BP declines over 1-3 min. Once mean BP at the cardiac level falls below $50 \mathrm{mmHg}$, loss of consciousness ensues within $7 \mathrm{~s}$. These patients do not have $\mathrm{OH}$ at other times.

Cardiovascular orthostatic hypotension $(\mathrm{cOH})$ results from intravascular hypovolemia, which is usually accompanied by compensatory tachycardia, or from decreased cardiac output. Causes include dehydration, venous pooling, cardiac dysrhythmias, cardiomyopathies, and cardiac valve disease.

Orthostatic pseudohypotension (pOH) consists of apparent $\mathrm{OH}$ when baseline supine $\mathrm{BP}$ is elevated, which may be due to concomitant recumbent hypertension, insufficient time at rest to establish a valid baseline, or fluctuation of baseline BP in the patient with labile hypertension. To compensate, a higher threshold of $30 \mathrm{mmHg}$ systolic BP change has been proposed to define $\mathrm{nOH}$ in such cases [3,7].

Numbers matter, and $\mathrm{OH}$ should not be diagnosed on the basis of symptoms without also measuring orthostatic BP. One must also look beyond the numbers and evaluate the clinical presentation of each patient, because not all $\mathrm{OHs}$ are the same in terms of pathophysiology or approach to treatment. 


\section{Compliance with ethical standards}

\section{Conflict of interests None.}

Funding sources None.

\section{References}

1. Fedorowski A, Hamrefors V, Sutton R, van Dijk JG, Freeman R, Lenders JW, Wieling W (2017) Do we need to evaluate diastolic blood pressure in patients with suspected orthostatic hypotension? Clin Auton Res. doi:10.1007/s10286-017-0409-7

2. Fedorowski A, Wahlstrand B, Hedner T, Melander O (2014) Systolic and diastolic component of orthostatic hypotension and cardiovascular events in hypertensive patients: the captopril prevention project. J Hypertens 32:75-81

3. Freeman R, Wieling W, Axelrod FB, Benditt DG, Benarroch E, Biaggioni I, Cheshire WP, Chelimsky T, Cortelli P, Gibbons CH, Goldstein DS, Hainsworth R, Hilz MJ, Jacob G, Kaufmann H,
Jordan J, Lipsitz LA, Levine BD, Low PA, Mathias C, Raj SR, Robertson D, Sandroni P, Schatz I, Schondorff R, Stewart JM, van Dijk JG (2011) Consensus statement on the definition of orthostatic hypotension, neurally mediated syncope and the postural tachycardia syndrome. Clin Auton Res Off J Clin Auton Res Soc 21:69-72

4. Gibbons CH, Freeman R (2015) Clinical implications of delayed orthostatic hypotension: a 10-year follow-up study. Neurology 85:1362-1367

5. van Wijnen VK, Harms MP, Go-Schon IK, Westerhof BE, Krediet CT, Stewart J, Wieling W (2016) Initial orthostatic hypotension in teenagers and young adults. Clin Auton Res Off J Clin Auton Res Soc 26:441-449

6. Wieling W, Krediet CT, van Dijk N, Linzer M, Tschakovsky ME (2007) Initial orthostatic hypotension: review of a forgotten condition. Clin Sci 112:157-165

7. Wieling W, Schatz IJ (2009) The consensus statement on the definition of orthostatic hypotension: a revisit after 13 years. J Hypertens 27:935-938 